\title{
The Development of the Trefftzian Methodology for Engineering Design Analysis
}

Link to publication record in Manchester Research Explorer

\section{Citation for published version (APA):}

Wearing, J. L., \& Sheikh, M. (1995). The Development of the Trefftzian Methodology for Engineering Design Analysis. Advances in Engineering Software, 24(0), 117-131.

\section{Published in:}

Advances in Engineering Software

\section{Citing this paper}

Please note that where the full-text provided on Manchester Research Explorer is the Author Accepted Manuscript or Proof version this may differ from the final Published version. If citing, it is advised that you check and use the publisher's definitive version.

\section{General rights}

Copyright and moral rights for the publications made accessible in the Research Explorer are retained by the authors and/or other copyright owners and it is a condition of accessing publications that users recognise and abide by the legal requirements associated with these rights.

\section{Takedown policy}

If you believe that this document breaches copyright please refer to the University of Manchester's Takedown Procedures [http://man.ac.uk/04Y6Bo] or contact uml.scholarlycommunications@manchester.ac.uk providing relevant details, so we can investigate your claim.

\section{OPEN ACCESS}




\title{
The development of the Trefftzian methodology for engineering design analysis
}

\author{
J. L. Wearing \& M. A. Sheikh \\ Department of Mechanical and Process Engineering, University of Sheffield, Sheffield, UK
}

\begin{abstract}
This paper reviews the developments in the Trefftzian Methodology, which have been undertaken by the authors at the University of Sheffield during the past fifteen years and the application of these developments to engineering design analysis. Initially, in the late 1970 s, this work concentrated on the Direct Boundary Element Method (DBEM) and the Indirect Boundary Element Method (IBEM). Unfortunately these methods, as they are normally formulated, give rise to singular integrals, which require special mathematical treatment, when the source and field points coincide on the boundary of the component being analysed. These singular integrals can however be eliminated by placing the source boundary outside the domain of the problem being analysed so that the field and source points never coincide. This technique is known as either the Regular Direct Boundary Element Method (RDBEM) or the Regular Indirect Boundary Element Method (RIBEM). In a further development of the RIBEM, based on the Trefftz Method, the continuous distribution of sources is replaced with sources distributed at discrete points on the source boundary. This modified Treffitz Method eliminates the integrations in the solution procedure, it provides a series solution in terms of the fundamental solution of the problem being analysed and is referred to as the Indirect Discrete Boundary Method (IDBM). The emergence of the IDBM provided the opportunity to develop a combined Boundary Element Finite Element technique which enables these methods to be used simultaneously in a single calculation, thereby exploiting their strengths and minimising their weaknesses. A number of case studies will be discussed in the paper to illustrate the developments in the Trefftzian Methodology and its application to engineering design analysis.
\end{abstract}

Key words: Trefftz, Indirect Discrete Boundary Method, thermal analysis, stress analysis.

\section{INTRODUCTION}

The three main numerical techniques for engineering analysis are the Finite Difference Method (FDM), the Finite Element Method (FEM), and the Boundary Element Method (BEM). The Finite Difference Method, which has been extensively applied to problems of fluid dynamics as well as stress analysis ${ }^{1}$ solves a problem as a pointwise approximation of its governing equations. However, the method is difficult to apply to problems involving irregular or complex geometries. This has led to the Finite Element Method becoming popular for solving a variety of engineering field problems, since it can be easily applied to many different types of geometry.

\subsection{The Finite Element Method}

The Finite Element Method ${ }^{2}$ uses a piecewise approximation to solve the governing equations by dividing the problem domain into a series of non-infinitesimal elements and applying these equations to each element. For an elastostatic problem, for example, the principle of minimum potential energy can be applied to the equilibrium of each element to form a 'stiffness matrix' which relates the nodal forces and displacements on each element. The stiffness matrices for all the elements can then be assembled into a global system of equations which are then solved for the unknown loads and displacements. 
The method can be easily applied for solving problems with complex geometries and has been successfully used for solving problems in fluid mechanics, ${ }^{3}$ potential flow, ${ }^{4}$ rock and solid mechanics, ${ }^{5}$ electromagnetism, ${ }^{6}$ crystal growth, ${ }^{7}$ acoustics ${ }^{8}$ and heat conduction; ${ }^{9}$ as well as problems involving elasto-plasticity and time-dependent deformation (creep) of materials. ${ }^{10}$

However, since the method only provides an approximation to the solution, it is often necessary to use a large number of very small elements to obtain accurate results. By employing a very fine mesh, the number of nodal points and hence the size of the stiffness matrix, can increase rapidly, occupying a large amount of the computer's available storage space. The solution of the global system of equations then becomes very difficult and time-consuming due to the size of the matrix. This is particularly noticeable in the solution of three-dimensional problems where each node has three degrees of freedom, and in problems where very fine meshes are essential for modelling stress behaviour accurately.

The size of the global stiffness matrix, and hence the problems associated with it, can be reduced by employing a Boundary Element Method which reduces the dimensionality of the problem by one.

\subsection{The Boundary Element Method}

Whereas the Finite Element Method attempts to find an approximate solution to a problem, the Boundary Element Method solves the equilibrium equations by integrating them analytically as the first step in the solution procedure. The advantage of this is that, since they have been integrated, only the boundary values of the problem need to be known. Hence, there is no need for either discretisation of the interior regions of a problem, or for evaluation of the function at any points other than those at the boundaries, before the problem can be solved. This greatly reduces the computational size of a model since a three-dimensional volume model can be modelled by its two-dimensional surfaces, and two-dimensional surface problems can be solved using one-dimensional line elements. The main disadvantages of the BEM are however the complex integrations required when formulating the initial equations and the resulting fully populated and asymmetric matrices.

The two main forms of the Boundary Element Method are the DBEM and the IBEM. The DBEM ${ }^{11}$ forms an equation directly relating the physical variables of a problem. The IBEM ${ }^{12}$ on the other hand, solves the problem for a set of imaginary sources, distributed around the boundary. The source distribution is then used to find the unknown displacements and tractions of the problem. This latter method is the easiest to apply in calculating results at points within a boundary element region since once the source distribution has been found it can be used to obtain the solutions for any other points without the need to re-solve the equations. Both these methods have been applied to a wide variety of problems, including elasticity, ${ }^{13}$ creep, ${ }^{14}$ fluid mechanics and electromagnetics. ${ }^{15}$

The solutions for each of these methods are written in terms of fundamental solutions which relate the displacements or tractions (scalar field variable and its derivative for a potential problem) at a field point on the boundary to the source strength at a source point on the boundary. The solution is obtained by integrating the effect of the source points over the boundary, and solving the resulting system of equations for each field point. The fundamental solutions are dependent upon the inverse of the distance between the field and source points, which causes problems to arise in the integrals when the location of the field and source points coincide, since here the fundamental solutions become singular. The treatment of these singularities has been discussed in detail by Banerjee \& Butterfield. ${ }^{16}$ However, Patterson \& Sheikh ${ }^{17}$ eliminated these singular points from the solution by moving the source boundary to a position outside the field boundary. This technique is known as the Regular Boundary Element Method, and it eliminates the singular integrals by separating the field and source boundaries so that the field and source points no longer coincide. The regular approach has been applied to both the Direct ${ }^{18}$ and Indirect ${ }^{19}$ Boundary Element Methods. The distance that the source boundary is placed away from the field boundary is controlled by a dimensionless factor $\lambda$, which is multiplied by the local element length to obtain the distance along the normal to each element at which the source boundary is positioned. If this factor, $\lambda$, is too small then the source boundary approaches the field boundary and the results approach the singularity situation. Conversely, if the physical and source boundaries are too far apart then rounding errors become significant and the accuracy for the solution drops. This behaviour of the $\lambda$ factor in the Regular Indirect Boundary Element Method (RIBEM) has been investigated ${ }^{19,20}$ to find a stable region.

\subsection{A modified Trefftz Method}

The next development in the RIBEM was by Patterson \& Sheikh ${ }^{21,22}$ who employed a modified Trefftz Method to replace the source distribution with a discrete set of source points on the source boundary. This produced the Indirect Discrete Boundary Method (IDBM), which contained no integrations, and thus eased the computation of the solution. The method has been successfully applied to a variety of field problems. ${ }^{23-26}$

By using the IDBM instead of the Finite Element Method (FEM) it is not only possible to significantly reduce the number of degrees of freedom of a problem, and hence the size of the equations, but the integrals which complicate the solution procedure in the BEM when the field and source boundaries coincide are 
eliminated. However, although the system of equations is smaller than that for the Finite Element Method for a similar problem, the stiffness matrix is both asymmetric and fully populated, as opposed to the banded matrix produced by the Finite Element Method.

\subsection{Coupled methods}

Comparing the BEM with the FEM, it can be seen that the former is ideal for reducing the number of degrees of freedom. However, they produce fully populated and asymmetric system equations. They are advantageously applied to linear problems including those with an exterior unbounded domain but they are less effective for non-linear problems. The FEM, on the other hand, is well recognised as an effective solver for problems which include such effects as non-homogeneous materials, non linear material properties, plasticity or creep and as a consequence require interior discretization.

Generally it is seen that where the FEM is weak, the BEM is strong and vice-versa. Moreover, the methods do not have any shared weaknesses. There is a clear attraction, therefore, in developing a combined approach, realizing the advantages of each technique whilst eliminating their disadvantages.

The combination of the Finite Element Method with the Singular Boundary Element Method is well documented. ${ }^{27-29}$ The coupling of the Indirect Discrete Boundary Method with the Finite Element Method has been achieved by adapting the equations for the boundary regions and allowing them to be combined with the finite element stiffness matrix as finite element substructures or super-elements. ${ }^{30,31}$ The coupling of the IDBM and the FEM is a more favourable approach since there are no singular integrations to perform. The resulting coupled method allows part of a problem to be modelled using the FEM and the rest of it using the IDBM. The resulting system of equations is smaller than the one obtained from a pure finite element model but allows a fine mesh of finite elements in regions where it is advantageous to use the FEM.

The combined FEM-IDBM was initially applied to two-dimensional potential ${ }^{32,33}$ and linear elastic ${ }^{34,35}$ problems. Later it was extended to axisymmetric problems, ${ }^{36,37}$ three-dimensional elasticity ${ }^{38}$ and elasticplastic fracture. ${ }^{39}$

\section{MATHEMATICAL FORMULATION}

The mathematical formulation of the various Boundary Element Methods has been discussed in detail by a number of authors. ${ }^{13,19,40,41}$ In this section the mathematics behind the Regular Indirect Boundary Element Method (RIBEM) is discussed and although the technique is described with reference to a planar problem in linear elasticity the same basic mathematical formulation applies for axisymmetric and threedimensional elasticity problems. The boundary element equations for elliptic problems such as steady state heat transfer or potential flow can also be formulated in a similar manner. This is followed by a description of the Trefftz Method and the way in which it has been modified to produce the Indirect Discrete Boundary Method (IDBM). Finally, coupling of the Finite Element Method, and the Indirect Discrete Boundary Method is described.

\subsection{Regular Indirect Boundary Element Method}

For a two-dimensional body (Fig. 1) in equilibrium under the action of a series of tractions and displacements, Navier's equilibrium equations must be satisfied. An indirect formulation of the Boundary Element Method can be made using a set of fundamental solutions based on Green's functions, ${ }^{16,42,43}$ which relate the variables at a field point $\left(x_{f}\right)$ to those at the source point $\left(x_{s}\right)$ on the boundary of the problem being analysed. The solution can be written as:

$$
u_{i}\left(x_{f}\right)=\left(G_{i j}\left(x_{f}, x_{s}\right) S_{j}\left(x_{s}\right)\right.
$$

where $G_{i j}$ is the fundamental solution and $S_{j}\left(x_{s}\right)$ is the value of the source function. Similarly, the tractions are related to the source functions by:

$$
t_{i}\left(x_{f}\right)=F_{i j}\left(x_{f}, x_{s}\right) S_{j}\left(x_{s}\right)
$$

in which $F_{i j}$ is the traction fundamental solution. Assuming that there are no body forces, the effect of all the tractions and displacements can be found by integrating the fundamental solutions over the surface

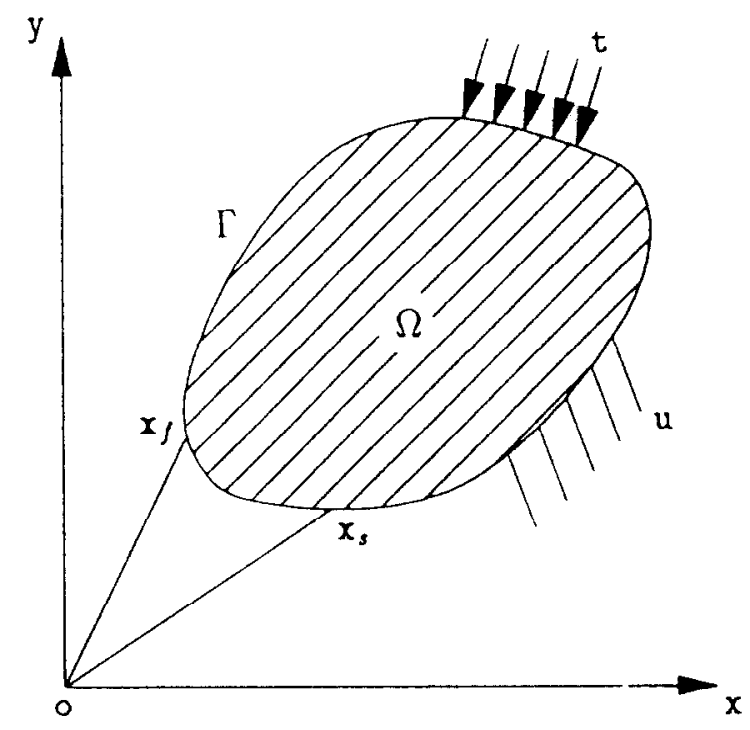

Fig. 1. Boundary element problem domain. 


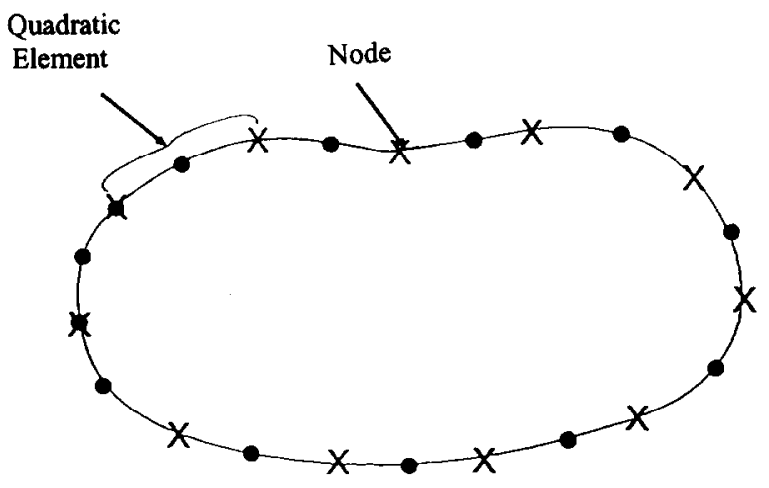

Fig. 2. Discretization of the boundary using quadratic line elements.

of the body, resulting in the following equations:

$$
\left.\begin{array}{l}
u_{i}\left(x_{f}\right)=\int_{\Gamma} G_{i j}\left(x_{f}, x_{s}\right) S_{j}\left(x_{s}\right) \mathrm{d} \Gamma \\
t_{i}\left(x_{f}\right)=\int_{\Gamma} F_{i j}\left(x_{f}, x_{s}\right) S_{j}\left(x_{s}\right) \mathrm{d} \Gamma
\end{array}\right\}
$$

The integrals in eqn (3) are evaluated by partitioning the boundary (or surface in a three-dimensional problem) of the problem into a series of elements (Fig. 2) with nodal points at which variables are evaluated. The integration is usually performed by employing a numerical procedure which transforms eqn (3) into the form:

$$
\begin{aligned}
u_{i}\left(x_{f}\right) & =\sum_{m=1}^{n}\left[\int_{\Gamma} G_{i j}\left(x_{f}, x_{s}\right) S_{j}\left(x_{s}\right) \mathrm{d} \Gamma\right] \\
t_{i}\left(x_{f}\right) & =\sum_{m=1}^{n}\left[\int_{\Gamma} F_{i j}\left(x_{f}, x_{s}\right) S_{j}\left(x_{s}\right) \mathrm{d} \Gamma\right]
\end{aligned}
$$

where $n$ is the number of elements and $\Gamma$ is the boundary (or surface) of each element over which the integration is performed.

The fundamental solutions $G$ and $F$ are functions of $\ln (1 / r)$ and $1 / r^{2}$ respectively for planar elasticity problems. The singularities are also encountered in the fundamental solutions for other problems and give rise to difficulties when the field and source points coincide causing the fundamental solutions to become singular. Methods have been developed for overcoming these problems, ${ }^{16,42}$ but these involve complex integration techniques. The Regular Indirect Boundary Element Method overcomes these problems by eliminating any singularities from the solution. ${ }^{41}$ This is achieved by moving the imaginary source boundary to a position outside the physical boundary of the problem as shown in Fig. 3.

\subsection{Indirect Discrete Boundary Method}

The basis of the Indirect Discrete Boundary Method is the Trefftz Method. ${ }^{52}$ The latter method was modified by employing the fundamental solutions in the

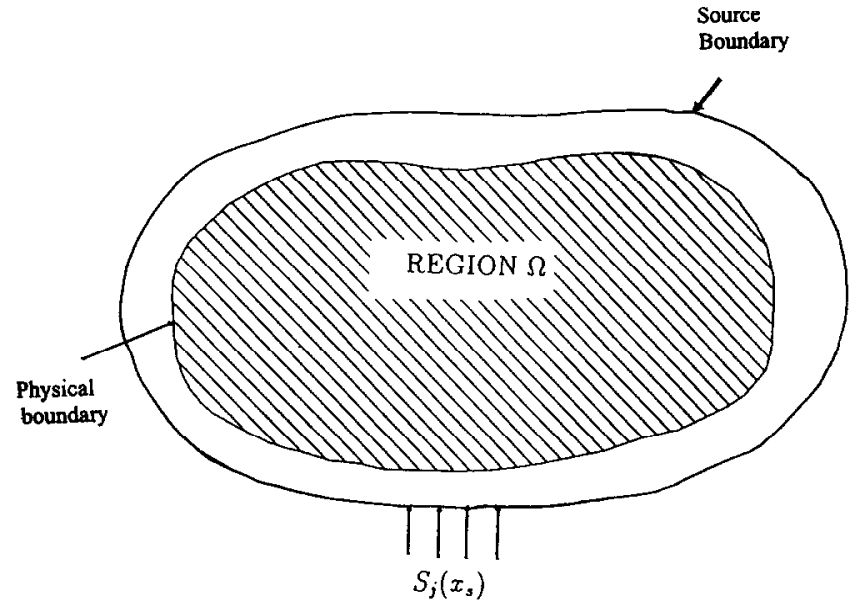

Fig. 3. Location of the source surface in the regular indirect boundary element method (RIBEM).

expansion. Moreover, a strategy similar to the one employed in the Regular Boundary Element Method was adopted whereby the singularities of the fundamental solutions are located outside the domain of the problem.

To describe a numerical model in the Indirect Discrete Boundary Method (IDBM), collocation points are defined on the surface with graded density similar to the boundary freedom nodes. Then to each collocation point a source location is defined. There is no constraint on the location of the singular point apart from the requirement that it be outside the domain of the problem being analysed as shown in Fig. 4. A solution is then sought as a linear expansion of the fundamental solutions. Such an expansion satisfies the governing equations so that only the boundary conditions remain to be satisfied. Given $N$ degrees of freedom in the expansion coefficients, and hence $N$ undetermined expansion coefficients, these are determined by point collocation on the boundary equating the trial solution to the given boundary conditions. A non-singular system of linear algebraic equations is thereby obtained which can be solved to produce the solution on the boundary.

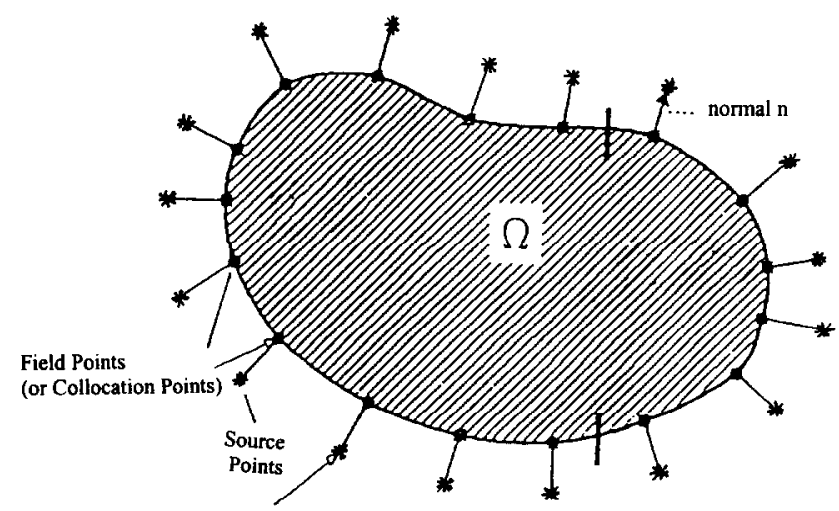

Fig. 4. Location of the source points in the indiscrete discrete boundary method (IDBM). 

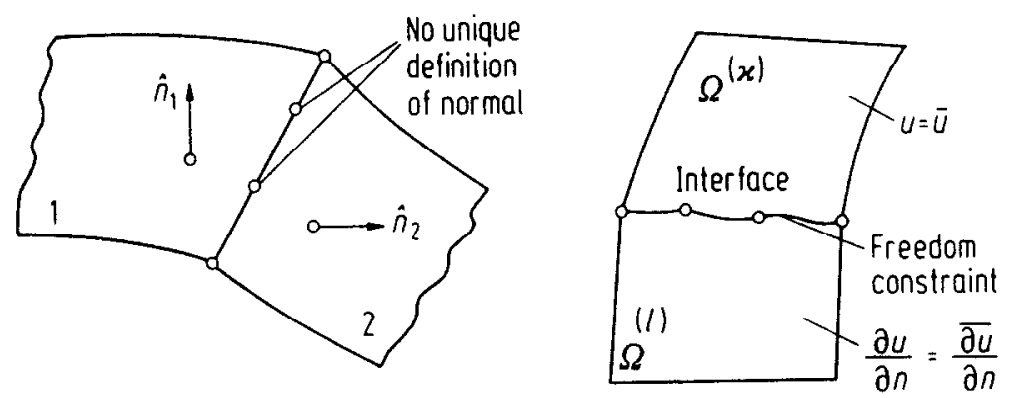

(a) Non-smooth surface (b) Freedom constraint at an interface where boundary condition type changes

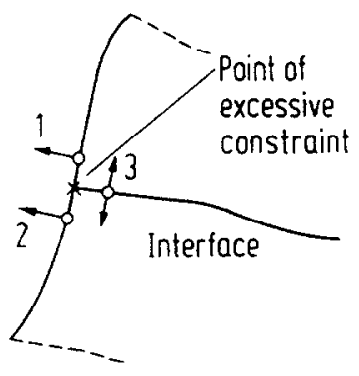

(c) Freedom constraint at a point where several surfaces meet

Fig. 5. Modelling problems with continuous elements in a conventional boundary element discretization.

It is obvious that in the IDBM, which is a modified Trefftz Method, the boundary integrals are replaced by a collocation process. This simplifies the problem by eliminating the integrations in eqn (4). Using the fundamental solutions $G$ and $F$ [eqns (1) and (2)] as a set of linearly independent functions, the solution for displacement, $u$, and traction, $t$, on the boundary and through the domain of a problem can now be expressed as:

$$
\begin{gathered}
u=\sum_{l=1}^{N} G_{l} S_{l} \\
t=\sum_{l=1}^{N} F_{l} S_{l}
\end{gathered}
$$

where $S_{l}$ are the magnitudes of the sources at the discrete points on the source boundary.

The equations for $\left\{u_{n}\right\}$ and $\left\{t_{n}\right\}$ at the boundary nodes are written in matrix form as:

$$
\begin{aligned}
& \left\{u_{n}\right\}=[G]\{S\} \\
& \left\{t_{n}\right\}=[F]\{S\}
\end{aligned}
$$

At every boundary node either the displacement or the traction is known so that assembling all the equations relating the known boundary conditions and the source intensities gives:

$$
\left\{\ddot{u}_{n}\right\}=[B]\{S\}
$$

where $\left\{\bar{u}_{n}\right\}$ is the vector of known boundary conditions, and $[B]$ is a matrix of both $G$ and $F$ fundamental solution contributions. Equation (9) can be solved to give $\{S\}$, the source intensities, which can then be used in eqns (7) and (8) to give the boundary solution as:

$$
\left.\begin{array}{l}
\{u\}=[G][B]^{-1}\left\{u_{n}\right\} \\
\{t\}=[F][B]^{-1}\left\{\bar{u}_{n}\right\}
\end{array}\right\}
$$

It can be seen that the Indirect Discrete Boundary Method greatly simplifies the numerical calculation, not only by replacing the integration but also by avoiding singularities in the fundamental solutions.

\subsubsection{Geometric representation}

For the geometric representation of the boundary or surface of a problem in the Indirect Discrete Boundary Method, various strategies may be employed. The purpose is solely to distribute freedom nodes around the boundary (or surface in a three-dimensional problem) in a way which accurately models the problem to produce a converged solution. For example, continuous elements (Fig. 5) may be employed when the freedom nodes are located at the element edge. Usually this poses no problem but the element edge may coincide with a discontinuity (such as a corner in a twodimensional problem) in the problem definition resulting in modelling ambiguities. Similarly, problems arise at the interface where the type of boundary condition changes. Yet again, when a numerical model is derived using subdomains, ${ }^{44}$ a similar problem arises where several subdomains meet or where two subdomains meet the exterior boundary.

To alleviate the modelling problems discussed above, a family of discontinuous and partially discontinuous elements have been developed. ${ }^{45-47}$ Some of these elements are shown in Fig. 6, and are used in distributing the freedom nodes in the IDBM as will be demonstrated in the case studies which are discussed in this paper.

\subsubsection{Subregioning}

Subregioning or the division of the domain into finite subdomains may be required to deal with nonhomogeneous problems or slender structures. Moreover, bandedness may be induced in the resulting matrices which are otherwise fully populated. ${ }^{44}$ Most conventional subregioning schemes resort to assembling the subregional matrices into one final banded matrix. ${ }^{48}$ However in the technique ${ }^{49}$ which is discussed in this paper, each subregion matrix is inverted and stored immediately after being set up. Hence, it eliminates the 


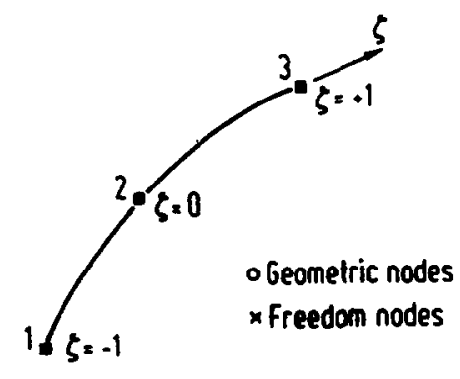

Continuous

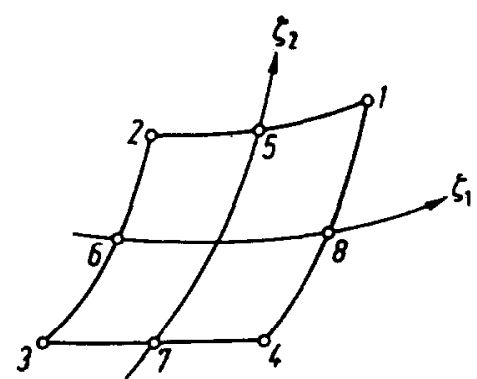

Continuous (quadratic)

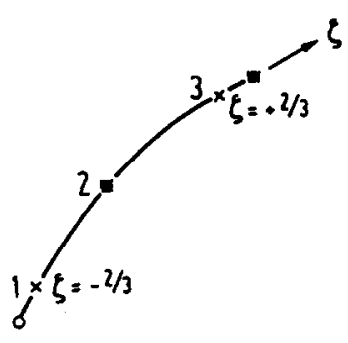

Discontinuous

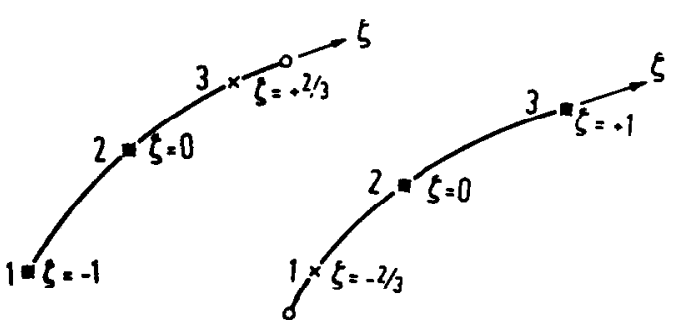

Partially Discontinuous

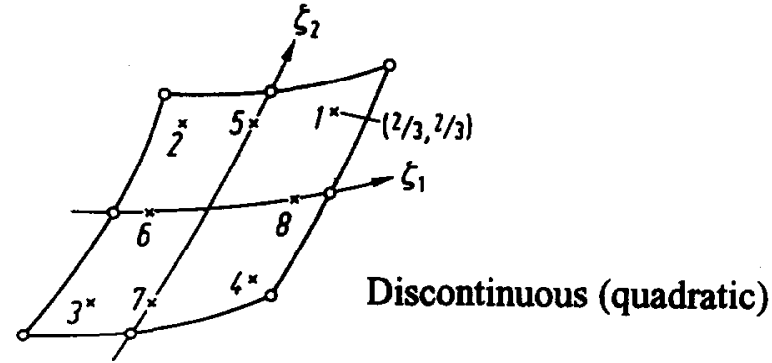

- Geometric nodes $\quad$ Freedom nodes
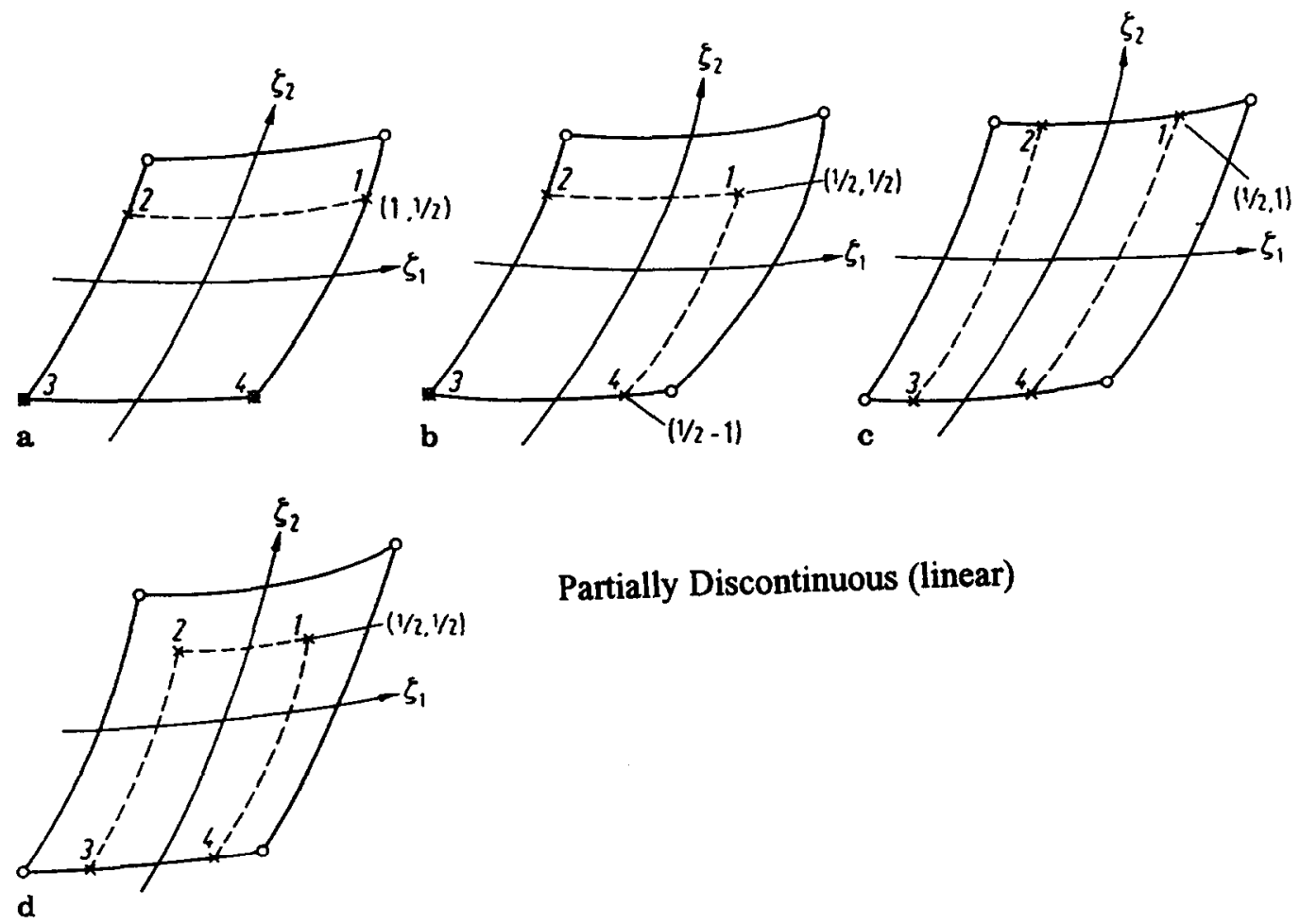

Partially Discontinuous (linear)

Fig. 6. Examples of continuous, discontinuous, and partially discontinuous line and surface elements. 

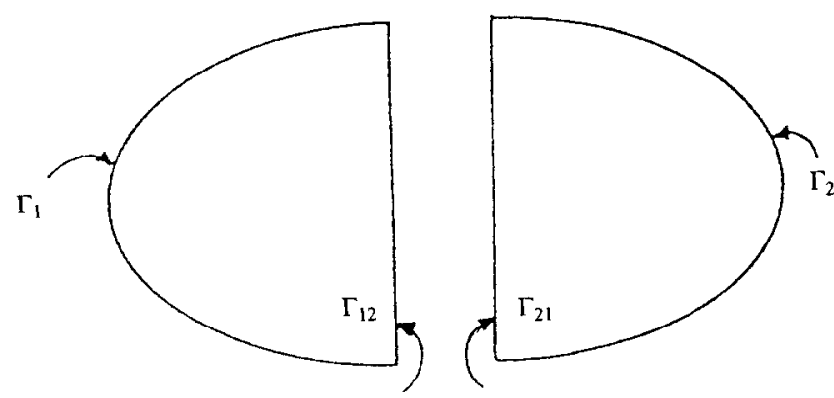

Fig. 7. Subregional domain.

need to use a reduction scheme, and less computing time is spent on inversions.

The formulation takes advantage of the fact that in the IDBM the field quantities, $u$ and $t$, are governed by separate equations indirectly linked by the distribution of the source densities. The interfacial relations of adjacent subregions are between the field quantities and not the source densities. This natural feature of the IDBM, therefore, gives the opportunity of treating each subregion separately.

To illustrate the technique, let the domain of the problem be divided into two subregions as shown in Fig. 7. Across the interface boundary compatibility and equilibrium must be enforced. Hence

$$
\begin{aligned}
& \left\{u_{1}\right\}=\left\{u_{2}\right\} \\
& \left\{t_{1}\right\}=-\left\{t_{2}\right\}
\end{aligned}
$$

Initially, as before, the following expression is formed for each subregion.

$$
\left\{\bar{u}_{n}\right\}=[B]\{S\}
$$

In this case $\left\{\bar{u}_{n}\right\}$, the boundary condition vector, contains some unknowns due to both tractions and displacements (or flux and potential for potential problems) being unknown at the interface.

For subregion one, eqn (10) becomes:

$$
\begin{aligned}
& \{u\}=[G]_{1}[B]_{1}^{-1}\left\{\bar{u}_{n}\right\}_{1} \\
& \{t\}=[F]_{1}[B]_{1}^{-1}\left\{\bar{u}_{n}\right\}_{1}
\end{aligned}
$$

Separating the known peripheral and the unknown interfacial field variables

$$
\left\{\bar{u}_{n}\right\}_{1}=\left\{\begin{array}{l}
\{u\}_{11} \\
\{u\}_{12}
\end{array}\right\}
$$

in which $\{u\}_{12}$ are displacements at the subregion interfacial boundary and $\{u\}_{11}$ are the displacements on the remainder of the subregion boundary.

Substituting eqn (15) into eqns (13) and (14) gives

$$
\begin{aligned}
& \{u\}=[G]_{1}[B]_{11}^{-1}\{u\}_{11}+[G]_{1}[B]_{12}^{-1}\{u\}_{12} \\
& \{t\}=[F]_{1}[B]_{11}^{-1}\{u\}_{11}+[F]_{1}[B]_{12}^{-1}\{u\}_{12}
\end{aligned}
$$

where:

$$
[B]_{1}^{-1}=\left[[B]_{11}^{-1}\left[B_{12}^{-1}\right]\right.
$$

Similarly, for subregion two

$$
\begin{aligned}
& \left.\{u\}=[G]_{2} \mid B\right]_{21}^{-1}\{u\}_{21}+[G]_{2}[B]_{22}^{-1}\{u\}_{22} \\
& \{t\}=[F]_{2}[B]_{21}^{-1}\{u\}_{21}+[F]_{2}[B]_{22}^{-1}\{u\}_{22}
\end{aligned}
$$

where:

$$
\left\{\bar{u}_{n}\right\}_{2}=\left\{\begin{array}{l}
\{u\}_{21} \\
\{u\}_{22}
\end{array}\right\}
$$

and

$$
[B]_{2}^{-1}=\left[[B]_{21}^{-1}[B]_{22}^{-1}\right]
$$

Now for the interfaces $\Gamma_{12}$ and $\Gamma_{21}$, the interfacial relationships at each freedom node are given by:

$$
\begin{aligned}
& \{u\}_{12}=\{u\}_{21} \\
& \{t\}_{12}+\{t\}_{21}=0
\end{aligned}
$$

Substituting eqns (17) and (20) into eqn (24) gives

$$
\begin{aligned}
& {[F]_{1}[B]_{11}^{-1}\{u\}_{11}+[F]_{1}[B]_{12}^{-1}\{u\}_{12}} \\
& \quad+[F]_{2}[B]_{21}^{-1}\{u\}_{21}+[F]_{2}[B]_{22}^{-1}\{u\}_{22}=0
\end{aligned}
$$

Substituting eqn (23) into (25) and rearranging gives

$$
\begin{aligned}
& \left([F]_{1}[B]_{12}^{-1}+[F]_{2}[B]_{21}^{-1}\right)\{u\}_{12} \\
& \quad=-\left([F]_{1}[B]_{11}^{-1}\{u\}_{11}+[F]_{2}[B]_{22}^{-1}\{u\}_{22}\right)
\end{aligned}
$$

Equation (26) can be used to set up $n_{12}$ equations ( $n_{12}$ is the number of interface freedom nodes) in order to solve for $n_{12}$ interface displacements $\{u\}_{12}$. A system of $n_{12}$ simultaneous equations is similarly constructed by considering the tractions on the interface. Hence a system of equations is formed as:

$$
\begin{aligned}
{[X]\{u\}_{12} } & =\{Y\} \\
\text { so that } \quad\{u\}_{12} & =[X]^{-1}\{Y\}
\end{aligned}
$$

Once $\{u\}_{12}$ is formed, the boundary condition vector $\left\{\bar{u}_{n}\right\}$ can be completed so that

$$
\{S\}=[B]^{-1}\left\{\bar{u}_{n}\right\}
$$

and hence

$$
\begin{aligned}
& \{u\}=[G]\{S\} \\
& \{t\}=[F]\{S\}
\end{aligned}
$$

The flow chart in Fig. 8 presents the algorithm and is self-explanatory.

\subsection{Coupling of Finite Element and Indirect Discrete Boundary Methods}

\subsubsection{Finite element energy formulation}

For an elastostatic problem, the Finite Element Method can be derived using an approach based on the minimization of the potential energy. ${ }^{2,50}$ For a body of region $\Omega$ with a boundary $\Gamma$, the potential 
Loop over regions

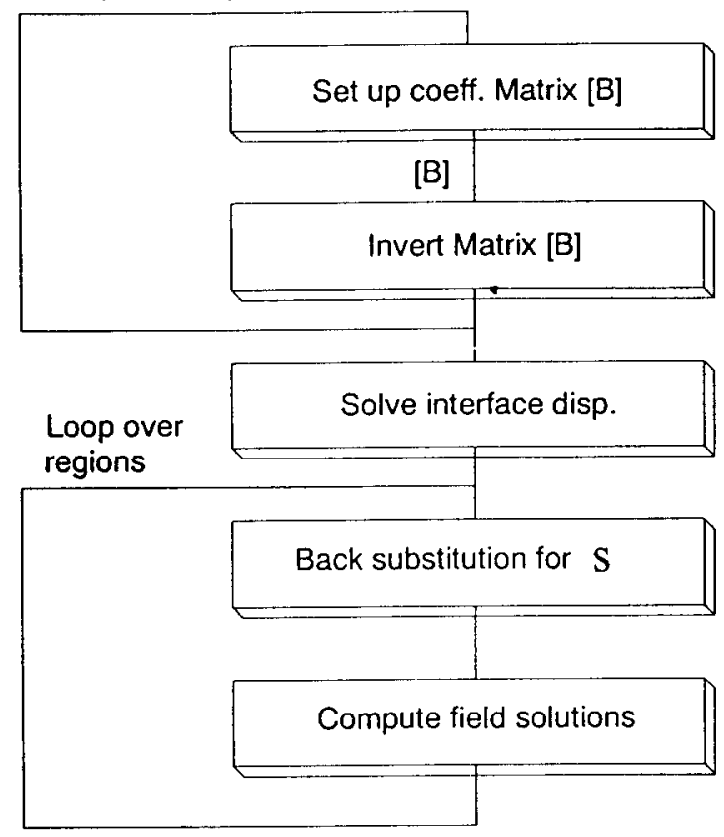

Fig. 8. Flow chart for subregioning algorithm.

energy is given as:

$$
\pi=\int_{\Omega} w(u) \mathrm{d} \Omega-\int_{\Omega} u b \mathrm{~d} \Omega-\int_{\Gamma} u p \mathrm{~d} \Gamma
$$

where the first term is a volume integral of the strain energy density $w(u)$ and the last two integrals are the external work terms in which $p$ represents the external boundary loads and $b$ represents the body forces. For a particular finite element, eqn (31) can be written in matrix form as:

$$
\pi=\frac{1}{2}\left\{u_{n}\right\}^{T}[k]\left\{u_{n}\right\}-\left\{u_{n}\right\}^{T}\left\{p_{n}\right\}
$$

where $\left\{p_{n}\right\}$ is the nodal force vector, $\left\{u_{n}\right\}$ is the nodal displacement vector and $[k]$ is the stiffness matrix given by:

$$
[k]=\int_{\Omega}[B]^{T}[D][B] \mathrm{d} \Omega
$$

where $[B]$ and $[D]$ are the strain-displacement and stress-strain matrices respectively.

Minimization of the potential energy (eqn 32) gives:

$$
[k]\left\{u_{n}\right\}=\left\{p_{n}\right\}
$$

and the overall system of equations is obtained by combining the equations for each element of the system to give an equation of the form:

$$
[K]\left\{U_{n}\right\}=\left\{P_{n}\right\}
$$

This system of equations contains unknowns for every node so that the size of the total system is related to the number of nodes. As the problem becomes more complex or a greater refinement is required, the system of equations can become large. A boundary technique offers the possibility of modelling only the boundary or surface of the problem so that the number of freedoms required for a satisfactory discretization is considerably reduced. However, as discussed earlier, a coupled Finite Element Boundary Element Method is desirable as it would allow a user to exploit the advantage of each method.

It is obvious that the final system of equations (eqn (10)) in the IDBM, relates tractions and displacements and as such is not directly compatible with the FEM which relates nodal displacements and forces (eqn (35)). A transformation is, therefore, required of eqn (10) to bring it in the same form as eqn (35).

\subsubsection{Boundary region super-element formulation}

A formulation based on the Indirect Discrete Boundary Method is now described which develops a system of equations analogous to a super-element (or substructure) in the Finite Element Method which enables coupling of the FEM and the IDBM to be achieved. It utilises Clapeyron's theorem, ${ }^{51}$ to transform eqns (7) and (8) into one relating nodal displacements to nodal forces.

By combining eqns (7) and (8), the source strengths $\{S\}$ can be eliminated so that the displacements and tractions are directly related by the following equation:

$$
\{t\}=[F][G]^{-1}\{u\}
$$

Clapeyron's theorem relates the strain energy, $w(u)$, the body forces, $b$, and the surface tractions, $t$, by means of the following equation:

$$
\int_{\Omega} w(u) \mathrm{d} \Omega=\frac{1}{2} \int_{\Omega} b u \mathrm{~d} \Omega+\frac{1}{2} \int_{\Gamma} t u \mathrm{~d} \Gamma
$$

Substituting eqn (36) into (37) and then into eqn (31) for the potential energy yields, in the absence of body forces, the following equation:

$$
\pi=\frac{1}{2} \int_{\Gamma}\{u\}^{T}[F][G]^{-1}\{u\} \mathrm{d} \Gamma-\int_{\Gamma}\{u\}^{T}\{p\} \mathrm{d} \Gamma
$$

As in the Finite Element Method, the solution is sought

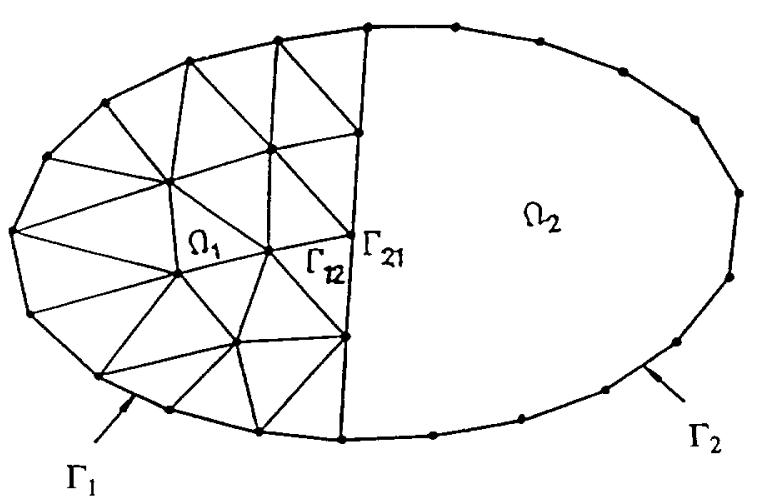

Fig. 9. Body divided into finite elements and a boundary region. 
when this equation is a minimum, and can be written as

$$
\int_{\Gamma}[F][G]^{-1}\{u\} \mathrm{d} \Gamma-\int_{\Gamma}\{p\} \mathrm{d} \Gamma=0
$$

or

$$
\{f\}=[k]\{u\}
$$

where

$$
[k]=\int_{\Gamma}[F][G]^{-1} \mathrm{~d} \Gamma
$$

and

$$
\{f\}=\int_{\Gamma}\{p\} \mathrm{d} \Gamma
$$

The stiffness matrices $[k]$ for each boundary region can be assembled to form a global stiffness matrix $[K]$ in a similar way to that used in the Finite Element Method.

The equations for the boundary regions have now been transformed into a system which is analogous to that of the Finite Element Method. This allows the two sets of equations to be combined into a single set of nodal displacements and forces linked via a global stiffness matrix. This means that a boundary region can be treated as a finite element substructure, and included in the global stiffness matrix as such. Thus, a global system matrix $[K]$ can be formed by combining the system matrices $[K]_{f e}$ and $[K]_{b}$, where $[K]_{f e}$ is the stiffness matrix of the finite element region and $[K]_{b}$ is the stiffness matrix of the boundary regions.

It should be noted that, although the IDBM as it was originally formulated contained no integrals, in transforming the equations to be compatible with the Finite Element Method, an integration process has been reintroduced. However this is only a simple surface integral which can be evaluated using the same technique as that used for integrating the finite element equations.

The combined technique is illustrated in Fig. 9 where the domain is divided into two substructures. Region $\Omega_{1}$ is modelled using the FEM while region $\Omega_{2}$ is modelled using the IDBM. The two substructures can be combined provided that at the intersection of the two regions the surfaces are compatible. This means that the finite element and boundary nodes must be coincident, and the shape functions used for the integration must be compatible. Provided that these conditions are adhered to, the combination of the two methods should present no problems.

Although only two subregions have been used here to demonstrate the coupling scheme, in fact theoretically there is no limit on the number of subregions which can be used, and the domain can be split into as many subregions as required. The equations for each subregion are then formulated using either method, before merging the stiffness matrices and nodal force vectors to give the final system of equations.

\section{CASE STUDIES}

Three examples are included here to demonstrate the application of the IDBM, and the use of the combined FEM-IDBM to real engineering design problems. The first two examples illustrate the use of the IDBM to a fully three-dimensional thermal analysis of (i) a motor pump casing, and (ii) a diesel engine piston. The third example illustrates the use of combined FEM-IDBM model for the stress analysis of a crane hook.

\subsection{Thermal analysis of a Glandless Motor Pump Casing}

This pump casing - Fig.(10) - was the object of study by Person ${ }^{53}$ and later by El-Sebai. ${ }^{54}$ It features large temperature gradients and also concave geometrics which cause modelling problems. Although the problem is axisymmetric, nevertheless, its three-dimensional analysis provides a good test for the method. The boundary conditions for the problem are shown in Fig. 11. The IDBM model for the casing is shown in Fig. 12. It is composed of a $30^{\circ}$ segment of the casing and has 11 subregions discretized by 91 discontinuous quadratic elements with 728 freedom nodes. In subregions 3 and 4 , it was necessary to move some freedom nodes to model the triangular geometry in that area. Figure 13 shows the axisymmetric and threedimensional finite element models which were also used for comparison with the IDBM solution.

The results from the IDBM analysis compare favourably with the axisymmetric finite element results, as shown in Fig. 14, where isothermals at a $15^{\circ}$ plane are plotted. A detailed comparison of the results is made in Table 1, where the temperature variation across the section $\mathbf{A}-\mathbf{A}$ is given for the IDBM and the axisymmetric finite element models. The maximum temperature difference, as given by the two models, is $1.4^{\circ} \mathrm{C}$ which is a difference of $0.53 \%$ between the two results.

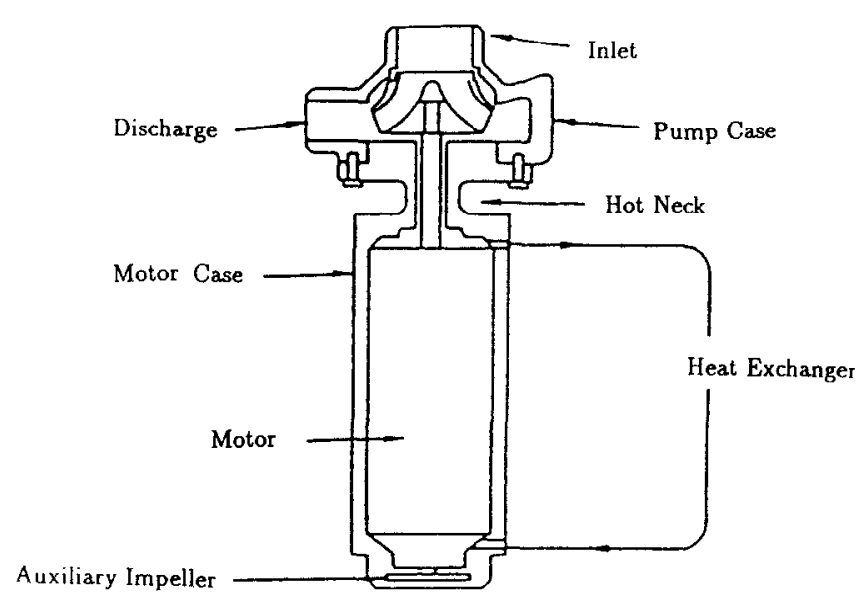

Fig. 10. Pump casing — pump and motor assembly. 

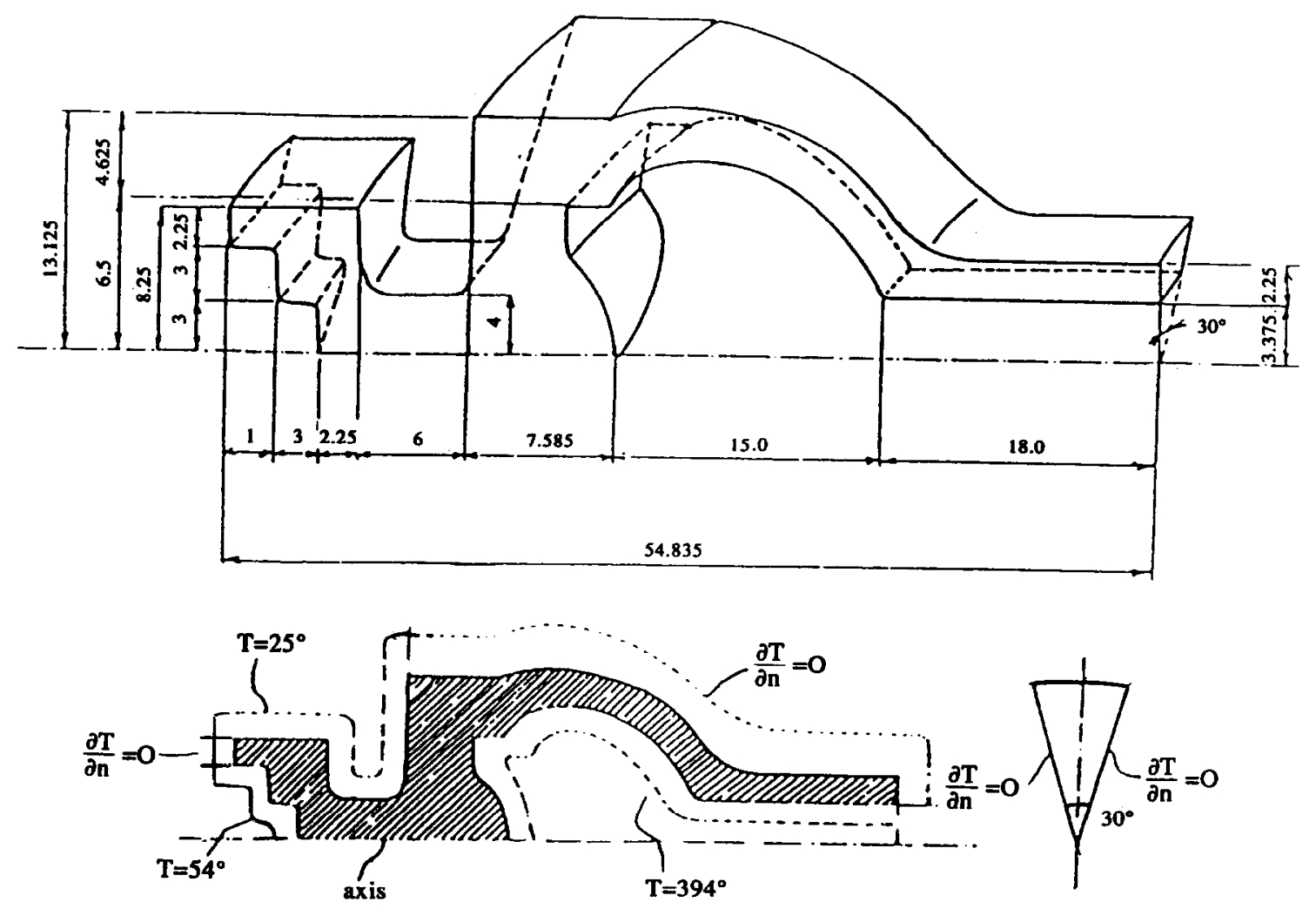

Fig. 11. Pump casing — geometry and boundary conditions.

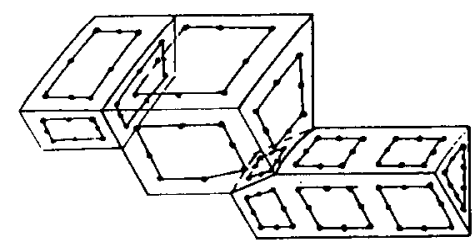

Model ling of subregions $1,2,3$.

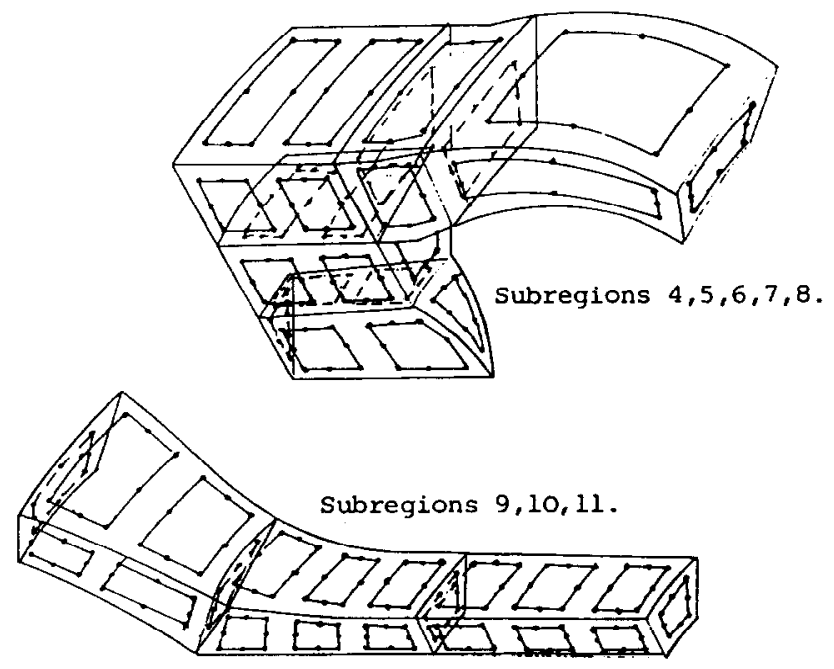

Fig. 12. Pump casing-IDBM model with 11 subregions.
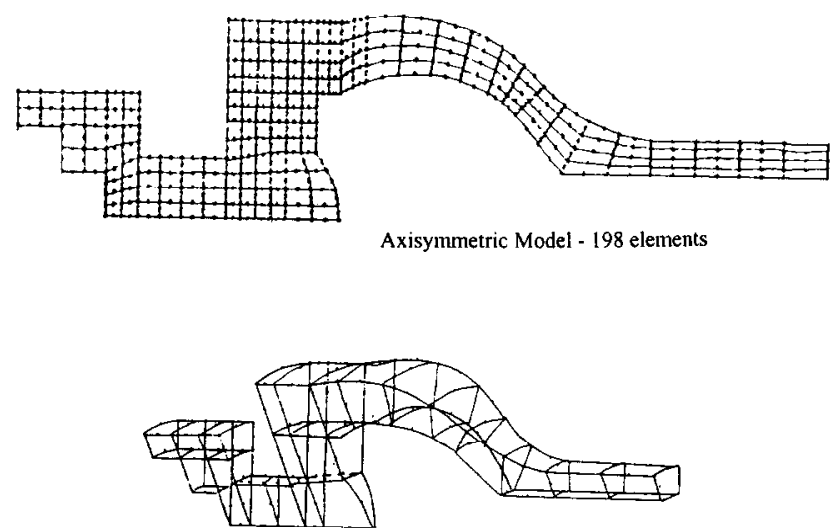

3-D Model - 22 Blocks; 8 elements/block ( 176 elements; 1199 nodes)

Fig. 13. Pump casing-axisymmetric and three-dimensional FE models.

\subsection{Thermal analysis of a diesel engine piston}

A large cast aluminium piston featuring an oval cooling gallery is analysed. Due to the symmetrical nature of the piston only a quarter segment needed to be modelled. The IDBM model employs 22 subregions (Fig. 15) with 224 eight noded discontinuous elements having 1792 degrees of freedom as shown in Fig. 16. The thermal boundary conditions for the problem were obtained from the earlier work. ${ }^{55-59}$ These boundary conditions 


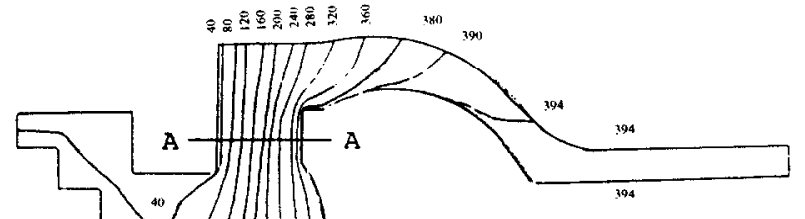

IDBM Solution

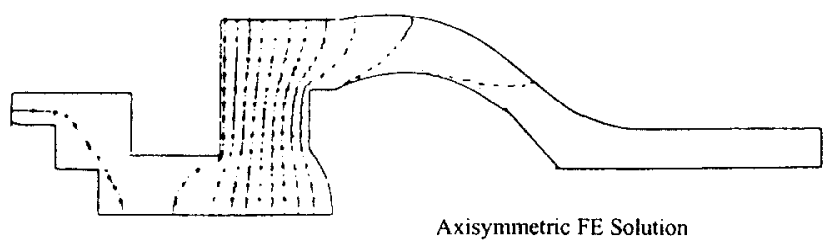

Fig. 14. Pump casing-computed isothermals.

Table 1. Pump casing - computed temperatures across Section A-A (as shown in Fig. 14)

\begin{tabular}{lcr}
\hline$x$-Dimension & $\begin{array}{c}\text { Axisymmetric } \\
\text { FE solution }\end{array}$ & $\begin{array}{c}\text { IDBM } \\
\text { solution }\end{array}$ \\
\hline 14.25 & 25.00 & 25.63 \\
14.75 & 53.88 & 54.08 \\
15.25 & 82.73 & 82.70 \\
15.75 & 111.60 & 111.40 \\
16.25 & 140.60 & 140.10 \\
16.75 & 169.90 & 169.10 \\
17.25 & 199.50 & 198.40 \\
17.75 & 229.70 & 228.40 \\
18.25 & 260.70 & 259.30 \\
18.75 & 292.60 & 291.20 \\
19.25 & 325.50 & 324.50 \\
19.75 & 359.40 & 359.00 \\
20.25 & 394.00 & 393.70 \\
\hline
\end{tabular}

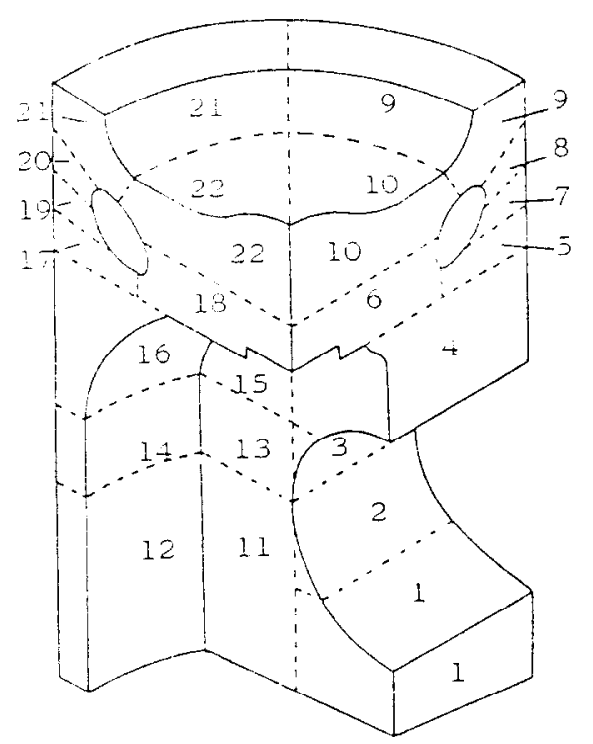

Fig. 15. Diesel engine piston-subregioning.

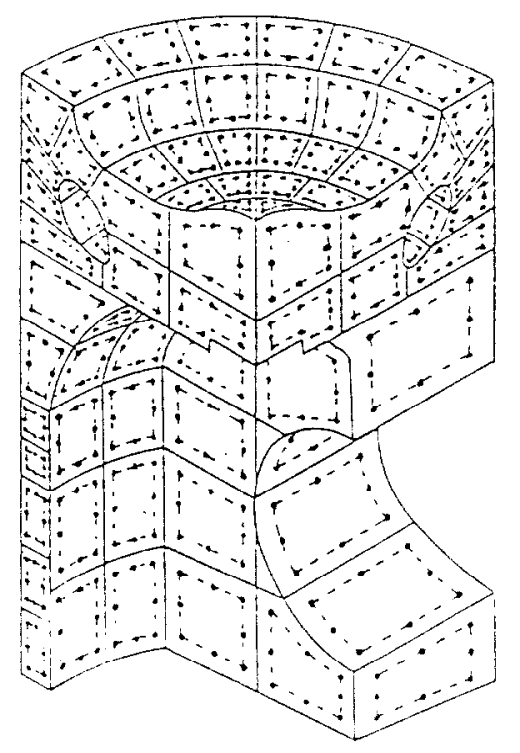

Fig. 16. Diesel engine piston-IDBM model.

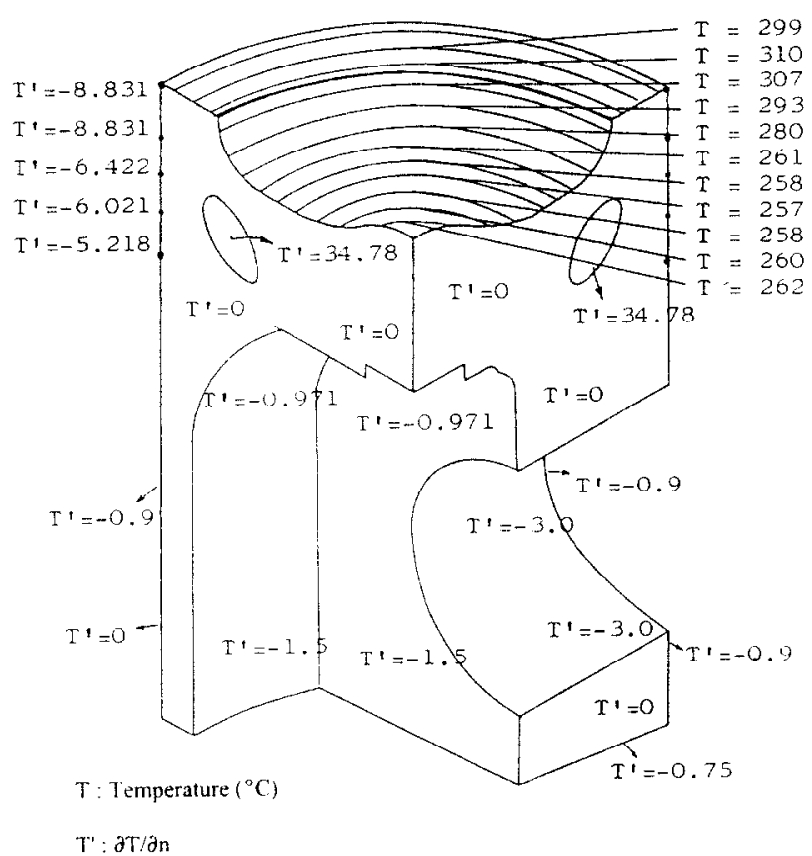

Fig. 17. Diesel engine piston-thermal boundary conditions

are shown in Fig. 17. Along the top surface of the piston, temperatures are specified along with potential normal derivatives (calculated from heat transfer coefficients) specified elsewhere.

The modelling of the cooling gallery caused some difficulty where is was necessary to use numerous subregions with smaller elements. This made the model more efficient but at the expense of a small increase in the data preparation time.

The results from the analysis are shown in Fig. 18 where isothermals are plotted. The results, again, compare favourably with three-dimensional finite element analyses previously conducted by the manufacturers. 


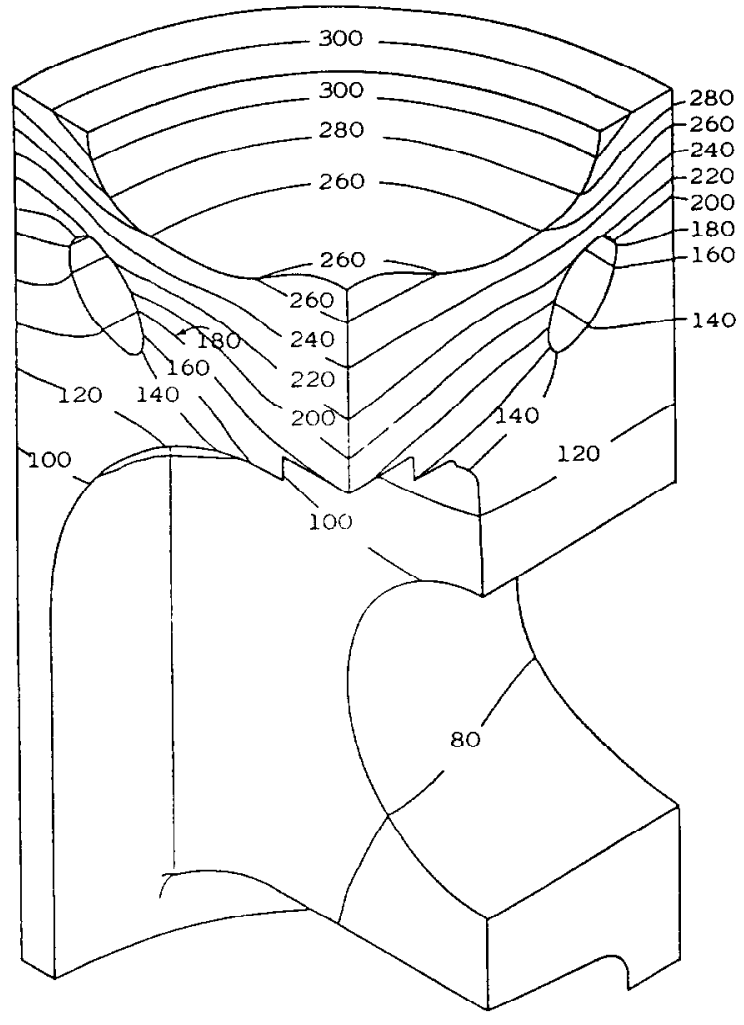

Fig. 18. Diesel engine piston-computed isothermals.

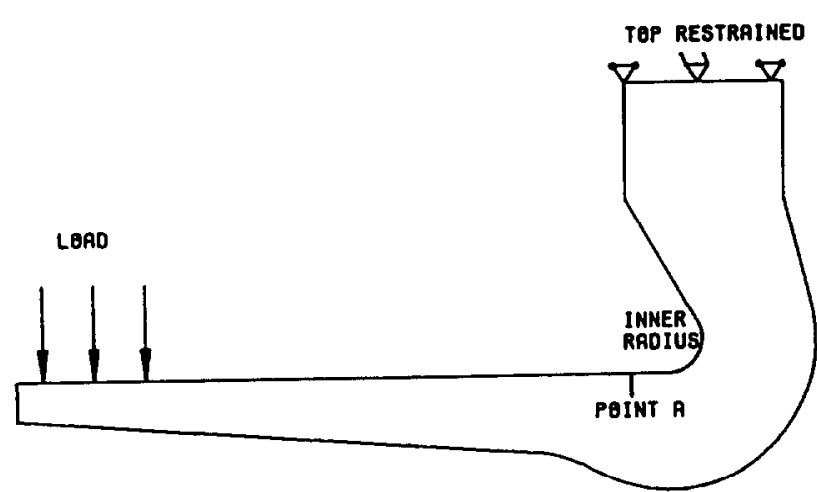

Fig. 19. Crane hook-geometry, loading and boundary conditions.

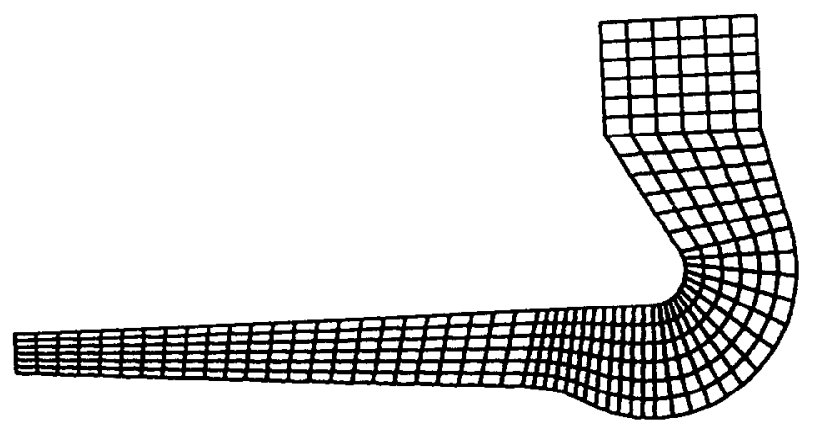

Fig. 20. Crane hook-FE model.

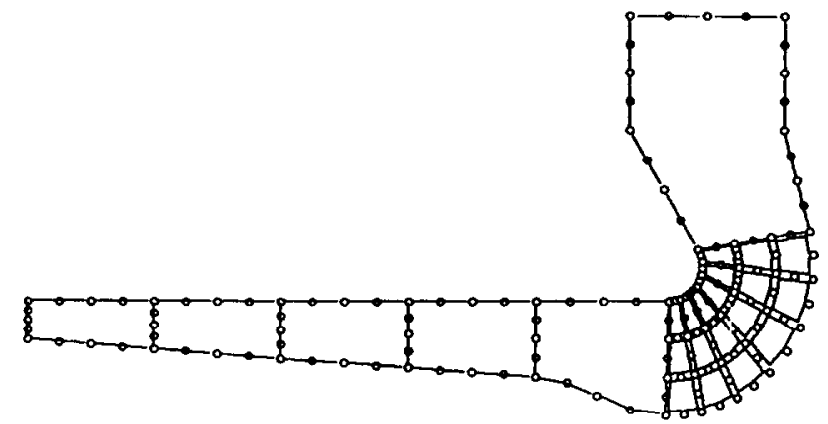

Fig. 21. Crane hook-combined FE-IDBM model.

\subsection{Coupled FEM-IDBM model of a crane hook}

This problem which arose from the design optimization exercise of a crane hook is shown in Fig. 19. Under static loading, a region of high stress is produced in the inner radius of the hook. Failures had occurred when cracks initiated in this region in the original design. As a result of these failures the problem was analysed using the photoelastic technique ${ }^{60}$ and as a result of this study an improved design was proposed. The photoelastic work had, on a tenth scale model, shown that, by increasing the inner radius the stresses could be reduced to acceptable levels. Here, the analysis is confined to the one final radius to demonstrate the application of the combined FEM-IDBM technique and the results from the combined model are compared with results from a finite element analysis.

The finite element model of the hook, which was earlier used for the analysis, is shown in Fig. 20. It comprises 360 eight-noded isoparametric elements. The combined FEM-IDBM model, as shown in Fig. 21, is constructed using eight-noded isoparametric finite elements around the hook bend and three-noded quadratic boundary elements for the remainder of the problem. The top area of the hook is modelled as one boundary region (super element) with 13 quadratic elements whilst the lower arm has five boundary regions (superelements) consisting of 41 quadratic elements.

Figure 22 shows the deformed shapes of the hook under load for the finite element and combined FEMIDBM analyses. These deformations are exaggerated for clarity.

From the computed stresses a stress concentration factor was calculated around the nodes along the inner radius of the bend. This is to enable the results to be compared with those obtained by photoelastic experiment. The stress concentration factor is the ratio of the maximum principal stress at the nodes to the maximum principal stress at a point on the horizontal arm just before the radius. This reference point, marked $\mathrm{A}$ on Fig. 19, was used in the photoelastic analysis as it marked the point where the stress distribution changed from a linear distribution of a simple cantilever to a non-linear distribution around the radius. The stress 

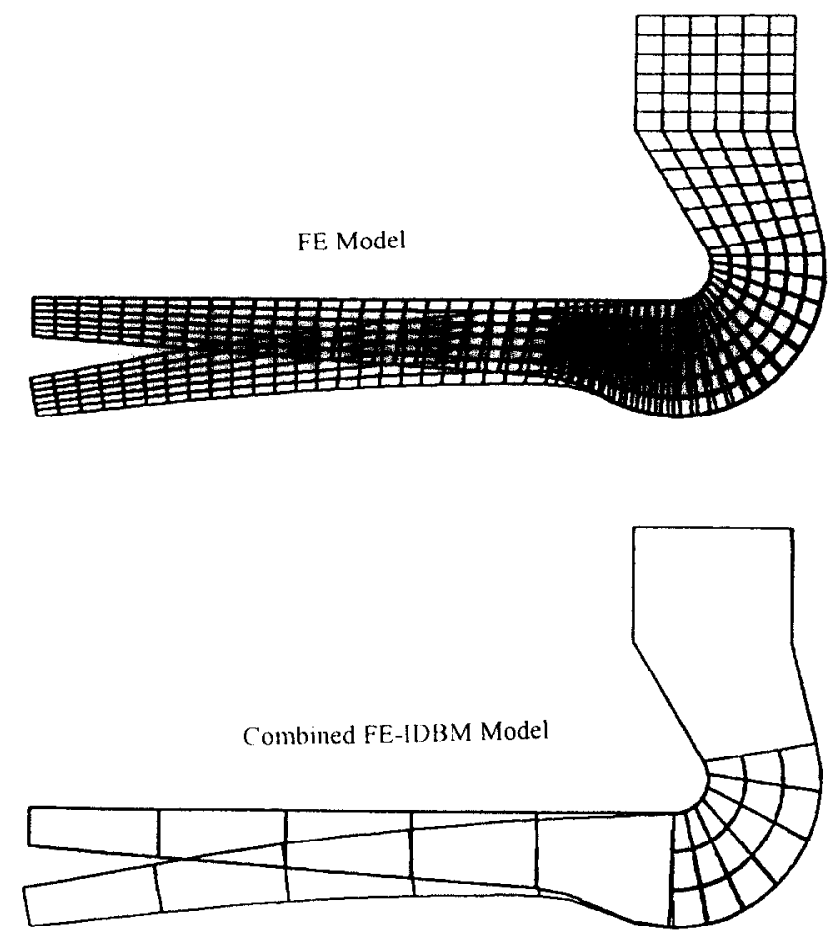

Fig. 22. Crane hook-deformed shapes.

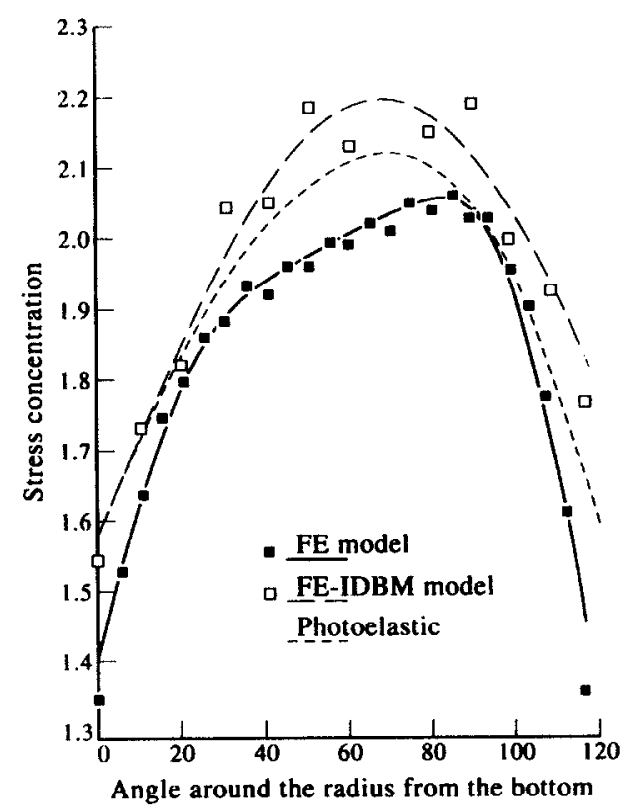

Fig. 23. Crane hook-principal stress variation around the inner radius.

concentration results are plotted in Fig. 23, as a function of angle round the radius from the bottom.

Comparison of deformed shape plots (Fig. 22) show that finite element and combined FEM-IDBM analyses give the same shape. The combined method gave the tip displacement which was about $6 \%$ lower than the finite element analysis. The stress concentration results (Fig. 23) are plotted by fitting a smooth curve through the stresses at the finite element nodes on the inner radius. The result for the maximum stress concentration factor using the combined method is $2 \cdot 2$, for the photoelastic technique, $2 \cdot 1$ and the FEM, 2.05. These are all within $8 \%$ of each other but the shape of the finite element distribution is slightly flatter than the other two, with the peak occurring further around the radius.

\section{DISCUSSIONS AND CONCLUSIONS}

Being a domain method, with freedoms distributed over the entire domain of the problem, the Finite Element Method would appear to carry a much higher modelling cost when compared with a Boundary Domain Technique with freedoms distributed over the boundary only.

One boundary domain technique which has been investigated in some detail in the past few years is the Boundary Element Method. Whilst this method has the advantage of only having boundary freedoms it also has a serious disadvantage in that in setting up the algebraic equations of the method, a series of integral equations of convolution type must be evaluated.

A number of other boundary domain techniques have also been developed. Among these is the Indirect Discrete Boundary Method which is a modified form of the Method of Trefftz. In this method, fundamental solutions of the given problem are employed as expansion functions the singularities of which are located outside the domain of the problem. The method greatly simplifies the numerical calculation by eliminating the integrations normally associated with Boundary Element Methods.

To prescribe a numerical model in the Indirect Discrete Boundary Method, collocation points are defined on the surface of the problem. These points are conveniently generated by using continuous, discontinuous and partially discontinuous boundary or surface elements depending upon the required mesh grading. Then to each collocation point a surface location is defined which is outside the domain. A solution is then sought as a linear expansion of the fundamental solutions. This expansion necessarily satisfies the governing equations so that only boundary conditions remain to be satisfied. The coefficients of expansion are determined by point collocation on the boundary by equating the trial solution to the given boundary conditions. A non-singular inhomogeneous system of linear algebraic equations is thereby obtained. The method has been successfully applied to planar, axisymmetric and fully three-dimensional analysis of problems in potential flow and linear elasticity.

Using the subregioning technique, the number of fundamental solutions required to be calculated is reduced considerably as these are only required between each source and every field point within a given subregion. The technique also facilitates the modelling of holes and concave geometries. 
Thermal analysis of the pump casing and the piston show that the Indirect Discrete Boundary Method is feasible for modelling components which have complex geometries and can give accurate results efficiently.

A unified technique, employing a coupled Finite Element-Indirect Discrete Boundary Method has also been developed. This technique allows optimal use of both methods and thus offers greater flexibility in modelling complex problems. For example, in problems involving plasticity, creep or fracture, it would be advantageous to model these regions using finite elements and the rest of the domain using a boundary technique.

A technique has been developed which modifies the Indirect Discrete Boundary Method and produces a final system of equations which is analogous to that of the Finite Element Method. The equations for the boundary region are then used by a finite element system as a substructure or super-element.

The crane hook problem demonstrates how a reduction in the size of a problem can be achieved by using boundary regions as finite element substructures - and yet obtain a solution of comparable accuracy.

\section{REFERENCES}

1. Forsythe, G. E. \& Wasow, W. R. Finite Difference Methods for Partial Differential Equations. John Wiley \& Sons, London, 1960.

2. Zienkiewicz, O. C. The Finite Element Method. McGrawHill, London, 1977.

3. Taylor, C. \& Hood, P. A numerical solution of the NavierStokes equations using the Finite Element Technique. Computational Fluids, 1973, 1, 73-100.

4. De Vries, G. \& Norrie, D. H. The application of the Finite Element Technique to potential flow problems. I. Appl. Mech., 1971, 38, 798-802.

5. Van Gudehus, G. Finite Elements in Geomechanics. John Wiley \& Sons, London, 1977.

6. Winslow, A. M. Numerical solution of the quasi-linear Poisson Equation in a non-uniform triangle mesh. $J$. Comput. Phys., 1966, 1, 149-72.

7. Crochet, M. J., Geyling, F. T. \& Van Schaftingen, J. J. Numerical simulation of the horizontal Bridgman growth of a gallium arsenide crystal. J. Crystal Growth, 1983, 65, 166-72.

8. Shuku, T. \& Ishihara, K. The analysis of the acoustic field in irregularly shaped rooms by the Finite Element Method. J. Sound Vibrat., 1972, 29, 67-76.

9. Zlamal, M. Finite Element Methods in heat conduction problems. In The Mathematics of Finite Elements and Applications II. ed. J. R. Whiteman. Academic Press, London, 1977.

10. Cry, N. A. \& Teter, R. D. Finite element elastic plastic creep analysis of two-dimensional continuum with temperature dependent material properties. Int. J. Comput. Struct., 1973, 3, 849-63.

11. Rizzo, F. J. An integral equation approach to boundary value problems of classical elastostatics. Quart. J. Appl. Math., 1967, 25, 83-95.

12. Jaswon, M. A. \& Symm, G. T. Integral Equation Methods in Potential Theory and Elastostatics. Academic Press, London, 1977.

13. Cruse, T. A. An improved boundary integral equation method for three- dimensional stress analysis. Int.J.Comput.Struct., 1974, 4, 741-57.

14. Telles. J. C. F. \& Brebbia, C. A. Viscoplasticity and creep using boundary elements. In Progress in Boundary Element Methods, Vol. 2, ed. C. A. Brebbia. Pentech Press, London, 1983.

15. Lean, M. H., Friedman, M. \& Wexler, A. Application of the boundary element method in electrical engineering problems. In Developments in Boundary Element Methods. Vol. 1, ed. P. K. Banerjee \& R. Butterfield. Applied Science Publishers, London, 1979.

16. Banerjee, P. K. \& Butterfield, R.,Boundary Element Methods in Engineering Science. McGraw-Hill, London, 1981.

17. Patterson, C. \& Sheikh, M. A. Regular boundary integral equations for stress analysis. In Boundary Element Methods in Engineering. ed. C. A. Brebbia, Springer, Berlin, 1981.

18. Patterson, C. \& El-Sebai, N. A. S. A regular boundary element method using non-conforming elements for potential problems in three dimensions. In Boundary Element Methods in Engineering, ed. C. A. Brebbia. Springer, Berlin, 1982.

19. Abdul Rahman, A. G. An investigation of the regular indirect boundary element method. $\mathrm{PhD}$ Thesis, University of Sheffield, 1985.

20. Patterson, C., Wearing, J. L., Sheikh, M. A. \& Abdul Rahman, A. G. On the application of the regular indirect boundary element method for axisymmetric thermal analysis using subregions. Proc. 2nd Int. Conf.on Boundary Element Technology - BETECH 87. ed. C. A. Brebbia \& W. S. Venturi. Computational Mechanics Publications, Southampton, 1987, pp.177-91.

21. Patterson, C. \& Sheikh, M. A. A modified Treffitz Method for fluid flow. Proc. 4th Int. Symp. Finite Element Methods in Flow Problems. ed. T. Kawai. Tokyo University Press, Tokyo, 1982, pp. 239-51.

22. Patterson, C. \& Sheikh, M. A. A modified Trefftz Method for stress analysis. Proc. Int. Conf. Finite Element Methods. ed. H. Guanggian \& Y. K. Cheung. Science Press, Beijing, China, 1982, pp. 973-80.

23. Patterson, C. \& Sheikh, M. A. On the use of fundamental solutions in the Trefftz Method for potential and elasticity problems. In Boundary Element Methods in Engineering. ed. C. A. Brebbia. Springer, Berlin, 1982.

24. Patterson, C., Sheikh, M. A. \& Scholfield, R. P. On the application of the indirect discrete boundary method for three dimensional design problems. Proc. Ist Int. Conf. Boundary Element Technology-BETECH 85. ed. C. A. Brebbia \& B. J. Noye. Springer, Berlin, 1985.

25. Wearing, J. L., Patterson, C., Sheikh, M. A. \& Scholfield, R. P. An indirect discrete boundary method for three dimensional thermal analysis using subregions. Proc. Int. Conf. on Computational Mechanics "86". ed. G. Yagawa \& S. N. Atluri. Springer, Berlin, 1986, pp. VIII.25-31.

26. Wearing, J. L., Patterson, C. \& Sheikh, M. A. An indirect discrete boundary method for fluid flow. Proc. 5th Int. Conf. Laminar and Turbulent Flow. ed. C. Taylor, W. G Habashi \& M. M. Hafez. Pineridge Press, Swansea, 1987, pp.23-34.

27. Kelly, D. W., Mustoe, G. G. W. \& Zienkiewicz, O. C. Coupling boundary element methods with other numerical methods. In Developments in Boundary Element Methods. ed. P. K. Banerjee \& R. Butterfield. Applied Science Publishers, London, 1979. 
28. Zienkiewicz, O. C., Kelly, D. W. \& Bettess, P. Marriage a la mode-The best of both worlds (finite elements and boundary integrals). In Energy Methods in Finite Element Analysis. John Wiley \& Sons, London, 1979.

29. Zienkiewicz, O. C., Kelly, D. W. \& Bettess, P. The coupling of the finite element method and boundary solution procedures. Int.J.numer.Meth.Engng, 1977, 11, $355-75$.

30. Wearing, J. L. \& Sheikh, M. A. A boundary element superelement method for coupling with the finite element method of sub-structuring. Proc. 12th Canadian Cong. Applied Mechanics - CANCAM-89. ed. M. A. Erki \& J. Kirkhope. Graphics Services Department, Carleton University, Ottawa, Canada, 1989, pp. 816-17.

31. Wearing, J. L., Sheikh, M. A. \& Hickson, A. J. On the use of coupled finite element boundary element models in numerical design analysis, Ibid., $802-03$.

32. Wearing, J. L., Sheikh, M. A. \& Noroozi, S. A boundary element super-element method for potential flow. Proc. 6 th Int.Conf.Numerical Methods in Laminar and Turbulent Flow, ed. C. Taylor. Pineridge Press, Swansea, 1989.

33. Wearing, J. L., Sheikh, M. A. \& Noroozi, S. On the application of a combined finite element boundary element method for thermal analysis. Proc. 11th Int. Conf. Boundary Element Methods. ed. C. A. Brebbia \& J. J. Connor. Computational Mechanics Publications, Southampton, 1989, pp. 95-106.

34. Wearing, J. L., Sheikh, M. A. \& Hickson, A. J. A combined finite element boundary element technique for stress analysis. Proc. 10th Int.Conf. on Boundary Element Methods. ed. C. A. Brebbia. Computational Mechanics Publications, Southampton, 1988.

35. Wearing, J. L., Sheikh, M. A. \& Hickson, A. J. On the application of a combined finite element-boundary element method for design analysis. Proc. 4th Int. Conf. on Boundary Element Technology - BETECH 89. ed. C. A Brebbia \& N. G. Zamani. Computational Mechanics Publications, Southampton, 1989, pp. 99-110.

36. Wearing, J. L., Sheikh, M. A. \& Saeed, R. A. The use of the combined finite element - discrete boundary element approach for axisymmetric elasto-plastic design analysis. Proc. 14th Int. Conf.on Boundary Element Methods. ed. C. A. Brebbia, J. Dominguez \& F. Paris. Computational Mechanics Publications, Southampton, 1992, Vol.2, pp. 235-46.

37. Wearing, J. L., Sheikh, M. A. \& Saeed, R. A. The analysis of axisymmetric heat conduction problems by the coupled finite element-boundary element method. Ibid., pp. 40719.

38. Wearing, J. L., Sheikh, M. A. \& Rahmani, O. A combined finite element - boundary element approach for three dimensional stress analysis. Proc. European Boundary Element Symposium-EUROBEM. ed. C. A. Brebbia. Computational Mechanics Publications, Southampton, 1990, pp. 31-41.

39. Wearing, J. L., Sheikh, M. A. \& Burstow, M. C. A combined finite element-boundary element approach for elasto-plastic analysis. Proc. Symp. Int. Assoc. for Boundary Element Methods-IABEM 90. ed. T. Cruse. Springer, Berlin, 1991, pp. 500-09.

40. Hickson, A. J. The combination of boundary elements and finite elements for stress analysis. PhD thesis, University of Sheffield, 1987.

41. Wearing, J. L., Abdul Rahman, A. G., Patterson, C. \& Sheikh, M. A. A regular indirect boundary element method for stress analysis. Proc. 9th Int. Conf. on
Boundary Element Methods. ed. C. A. Brebbia, W. L. Wendland \& G. Kuhn. Computational Mechanics Publications, Southampton, 1987, pp. 183-98.

42. Brebbia, C. A. Progress in Boundary Element Methods. Vol.1, Pentech Press, London, 1981.

43. Green, C. D. Integral Equation Methods. Thomas Nelson \& Sons, London, 1969.

44. Lachat, J. C. Further development of boundary integral techniques for elastostatics. PhD Thesis, University of Southampton, 1975.

45. Patterson, C. \& Sheikh, M. A. Interelement continuity in the boundary element method. In Progress in the Boundary Element Method. ed. C. A. Brebbia. Vol. 3, Springer, Berlin, 1984.

46. Patterson, C. \& Sheikh, M. A. Discontinuous boundary elements for heat conduction. Proc. 2nd Int. Conf. on Numerical Methods in Thermal Problems. ed. R. W. Lewis, K. Morgan \& B. A. Schrefler. Pineridge Press, Swansea, 1981, pp. 25-34.

47. Patterson, C. \& Sheikh, M. A. Partially discontinuous boundary elements for heat conduction. Proc. 3rd Int. Conf. on Numerical Methods in Thermal Problems. ed. R. W. Lewis. Pineridge Press, Swansea, 1983, pp. 25-34.

48. Cruse, T. A. Numerical solutions in three dimensional elastostatics. Int. J. Solids Structures, 1972, 5, 1259-74.

49. Patterson, C., Wearing, J. L. \& Sheikh, M. A. A review of recent developments in boundary domain techniques. In Boundary Element Methods-Theory and Application. Institute of Physics Publication, London, 1986.

50. Avantes Oliveira, E. R. Theoretical foundations of the finite element method. Int. J. Solids Structures, 1968, 4, 929-52.

51. Love, A. E. H. A Mathematical Theory of Elasticity. Cambridge University Press, 1982.

52. Trefftz, E. En Gegenstrück Zum Ritz Schen Verfahren. Proc. 2nd Int. Cong. Applied Mechanics, Zurich, 1926.

53. Person, $P$. The practical use of computer aided techniques in pump casing stress analysis. Proc. Conf. on Computer Aided Design of Pumps and Fans. Mechanical Engineering Publications, London, 1973, pp. 91-100.

54. El-Sebai, N. A. S. (1982) An investigation of the regular boundary element method in three dimensions. $\mathrm{PhD}$ Thesis, University of Sheffield, 1983.

55. Hasebe, T., Kaminishizono, T., Arai, F., Machida, S., Fiyikake, K. \& Takahashi, R. An analysis of a spark ignition enginc piston. Proc. 19th Int. FISITA Congress. Melbourne, 1982.

56. Woshni, G. \& Fuiger, J. Determination of local heat transfer coefficients at the piston of a high speed diesel engine by evaluation of measured temperature distribution. Paper SAE/SP-79/449, Society of Automotive Engineers, 1979.

57. Holt, I. S. \& Parsons, B. Finite element stress analysis in the medium speed diesel engine. ASME Publication, 80DGP-10, American Society of Mechanical Engineers, 1979.

58. Munro, R. \& Griffiths, W. J. The application of predictive techniques in the design and development of medium speed diesel engine pistons. Proc. 13th Int. Cong. on Combustion Engines. Vienna, 1979.

59. Luton, P. \& Sinha, S. K. Development of analytical aspects of diesel engine design. Proc. 12th Int. Cong. on Combustion Engines. Tokyo, 1977.

60. Kenny, B. Internal Report, Department of Mechanical Engineering, University of Sheffield, 1974. 